\title{
A CLINICAL COMPARISION OF INTRAOPERATIVE, RECOVERY, AND POSTOPERATIVE EFFECTS OF IV PARACETAMOL WITH IV DICLOFENAC IN TONSILLECTOMY
}

Rupa Kumari Aㄹ, Deepraj Singh B², Rajshekar Reddy ${ }^{3}$

\section{HOW TO CITE THIS ARTICLE:}

Rupa Kumari A, Deepraj Singh B, Rajshekar Reddy. "A Clinical Comparision of Intraoperative, Recovery, and Postoperative Effects of IV Paracetamol with IV Diclofenac in Tonsillectomy". Journal of Evolution of Medical and Dental Sciences 2014; Vol. 3, Issue 47, September 25; Page: 11436-11445,

DOI: $10.14260 /$ jemds/2014/3495

ABSTRACT: Intravenous Paracetamol is a centrally acting antipyretic and analgesic, has less gastrointestinal and platelet inhibiting side effects and is clinically better tolerated. IV Paracetamol could potentially provide adequate perioperative analgesia as a single agent for mild to moderate pain. Diclofenac a NSAID that mediate anti-inflammatory, analgesic and platelet inhibiting effects. NSAIDS are effective in peri operative setting for mild to moderate pain, but their usefulness may be limited due to their tendency to cause gastrointestinal and surgical site hemorrhage and renal failures in high risk patients. The present study conducted in 50 patients aged between 12-20 yrs who are scheduled for elective Tonsillectomy under general anesthesia in ENT hospital, Osmania Medical College, Hyderabad. To conclude that Paracetamol given every $6^{\text {th }}$ hourly parenterally can be used for intra operative and postoperative analgesia (mild to moderate pain) in elective Tonsillectomy in view of its good quality of analgesia, and its anti-pyretic effect.

KEYWORDS: Perioperative pain, Analgesia, Diclofenac, Paracetamol infusion.

INTRODUCTION: Pain is as old as mankind. Pain is defined by International Association for the study of pain (IASP) as "an unpleasant sensory and emotional experience associated with actual or potential tissue damage" ${ }^{1} \mathrm{An}$ outstanding contribution in the field of pain research was Gate control theory of pain by Melzack and Wall in 1965, which provided a sound scientific basis for understanding pain mechanics. Use of opioids for Intraoperative and postoperative analgesia is associated with opioid related side effects such as nausea, vomiting, sedation, respiratory depression.

NSAIDS have the potential advantages over opioids having less respiratory depression, nausea, vomiting, having antipyretic, anti-inflammatory effect and provide equipotent analgesia ${ }^{2}$. In mild to moderate pain NSAIDS may be adequate to provide optimal analgesia. NSAIDS and acetaminophen are the foundation of multimodal analgesia. Intravenous route is a preferred route for the intraoperative and postoperative pain management. Whenever faster onset of analgesia is desired and patient is unable to take medications by mouth.

Iv Paracetamol is a centrally acting antipyretic and analgesic has less gastrointestinal and platelet inhibiting side effects and is clinically better tolerated. IV Paracetamol ${ }^{3}$ could potentially provide adequate peri operative analgesia as a single agent for mild to moderate pain.

Diclofenac is a NSAID that mediate anti-inflammatory, analgesic and platelet inhibiting effects. NSAIDS are effective in peri operative setting for mild to moderate pain, but their usefulness may be limited due to their tendency to cause gastrointestinal and surgical site hemorrhage and renal failures in high risk patients. 
MATERIAL AND METHODS: The present study conducted in 50 patients aged between 12-20 yrs who are scheduled for elective Tonsillectomy under general anesthesia in ENT hospital, attached to Osmania Medical College, Hyderabad.

After approval from the Departmental ethics committee and written informed consent from the patients, a randomized study was conducted on 50 patients, planned for elective tonsillectomy surgery under general anaesthesia. Patients are selected between 12 to 20 years of age comprising both sexes who had no systemic disorders and are divided into 2 groups of each group containing 25 patients.

GROUP P: Paracetamol group.

GROUP D: Diclofenac group.

Monitoring used NIBP, Pulse oximeter, EtCo2, Temperature.

Drugs used: Paracetamol 15mg/kg iv over $10 \mathrm{~min}$ as infusionand Diclofenac $1 \mathrm{mg} / \mathrm{kg}$ iv in $100 \mathrm{ml}$ NS over 10 min as infusion.

All the patients are allocated into 2 groups randomly. The patients in group ' $\mathrm{P}$ ' received Paracetamol iv 15mg/kg over $10 \mathrm{~min}$ and patients in group ' $\mathrm{D}$ ' received Diclofenac iv1mg/kg in $100 \mathrm{ml}$ NS over $10 \mathrm{~min}$, before the induction. Both drugs were administered $15 \mathrm{~min}$ before the induction.

Inclusion Criteria: Pts with ASA grade I, Patients aged between 8 and 20 yrs.

Exclusion Criteria: Patients with abnormal Liver and Renal function tests, H/O hypersensitivity to NSAIDS. Temperature more than $99.6 \mathrm{~F}$, Patients who are on concomitant medication (anticonvulsants, corticosteroids, or antihistamines) that might interfere with pain evaluation.

A uniform standard technique of general anesthesia with endotracheal intubation and controlled ventilation was planned for all patients. Pre anesthetic checkup was done for all patients and baseline investigations were ordered as per requirement. 15 min before the scheduled time IV cannulation was done after shifting the patient into the waiting area of the operation theatre.

Patient was premedicated with Glycopyrolate $4 \mathrm{mcg} / \mathrm{kg}$, Ondansetron $10 \mathrm{mcg} / \mathrm{kg}$, Rantac $2 \mathrm{mg} / \mathrm{kg}$ given intravenously slowly. Patients were randomly allocated to receive one of the analgesic among the two (iv Paracetamol iv $15 \mathrm{mg} / \mathrm{kg}$ over $10 \mathrm{~min}$ and Diclofenac iv1mg/kg in $100 \mathrm{ml}$ NS over 10 min before the surgery).

On arrival into operation theatre Patient was connected to NIBP, pulse oximeter probe and electrocardiographic leads (limb lead-2). Baseline PR, BP and Spo2 were recorded. After pre oxygenation the patient induction was done with Propofol $2 \mathrm{mg} / \mathrm{kg}$ and endotracheal intubation was performed by using Inj suxamethonium $2 \mathrm{mg} / \mathrm{kg}$ and with an appropriate size oral cuffed, portex endotracheal tube by the aid of appropriate Macintosh laryngoscope blade.

After intubation anesthesia was maintained with Oxygen 33\%, Nitrous oxide $66 \%$, muscle relaxant Inj. Atracurium $0.5 \mathrm{mg} / \mathrm{kg}$ and Sevoflurane in the range of $1.5-2 \%$. IPPV was given using circle absorbing system connected to the datex ohmeda anesthesia work station at a rate of 14 breaths $/ \mathrm{mt}$ and $8 \mathrm{ml} / \mathrm{kg}$ tidal volume. ETCO2 maintained between 30-35 mm Hg. Intra operative IV fluids were given according to the protocol, blood loss. 
Ringer lactate and Dextrose NS were used for intraoperative fluid therapy. Vital data was recorded at induction, intubation and every $15 \mathrm{~min}$ interval during intraoperative period. The parameters recorded were pulse rate systolic blood pressure diastolic pressure, mean arterial pressure.

In all patients the duration of surgery was around $45 \mathrm{~min}$.After completion of surgery the neuromuscular blockade was reversed with Neostigmine $60 \mathrm{mcg} / \mathrm{kg}$ and Glycopyrolate $1 \mathrm{mcg} / \mathrm{kg}$. Vital data was recorded during recovery period. Patients were transported to the post-operative ward after confirming an adequate level of consciousness and intact reflexes and were observed for $6 \mathrm{hrs}$ in postoperative period for analgesia, hemodynamics, and temperature.

Postoperative pain assessment was done by using Visual analogue scale. Vital data was recorded regularly at 2 hrs intervals in the postoperative period. Observation and results were evaluated and compared between the two groups.

Post operatively, the patients in both the groups were observed for 6 hours and recording were done at: 0 hours (as soon as the patient was shifted), 2 hours, 4 hours, 6 hours.

Table 1 and graph 1: Shows Pulse Rate (per minute) changes in two groups: at different time intervals Intra operatively.

\begin{tabular}{|l|c|c|c|c|}
\hline & Group P (MEAN \pm SD) & Group D (MEAN \pm SD) & Values & significance \\
\hline Induction & $79.08( \pm 5.980)$ & $79.68( \pm 5.62)$ & 0.722 & NS \\
\hline Intubation & $88.2( \pm 5.38)$ & $88.52( \pm 3.41)$ & 0.806 & NS \\
\hline $15 \mathrm{~min}$ & $83.36( \pm 4.13)$ & $85.36( \pm 3.60)$ & 0.049 & HS \\
\hline $30 \mathrm{~min}$ & $82.76( \pm 4.56)$ & $85.12( \pm 2.93)$ & 0.045 & HS \\
\hline $45 \mathrm{~min}$ & $81.56( \pm 4.69)$ & $84( \pm 3.21)$ & 0.031 & HS \\
\hline
\end{tabular}

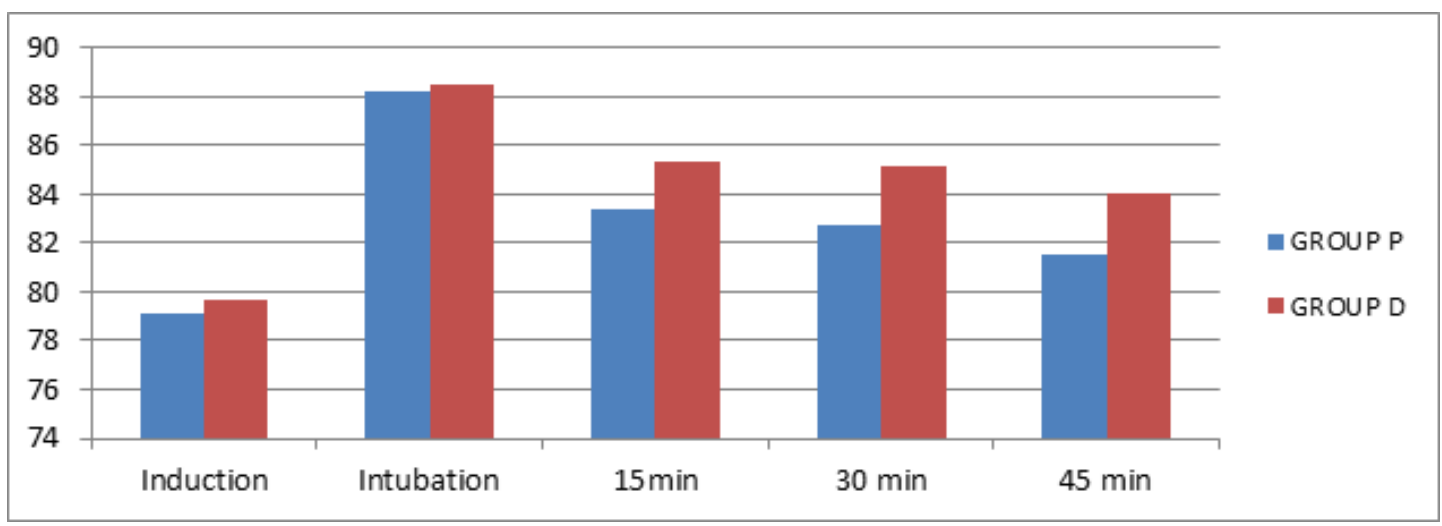

Pulse rate recordings were made at different time intervals intra operatively during induction, intubation, $15 \mathrm{~min}, 30 \mathrm{~min}$, $45 \mathrm{~min}$.

It can be inferred from the values in the table and graph that there is no statistical significant difference between group $\mathrm{P}$ and group $\mathrm{D}$ during induction and intubation. And in Group D there is rise in $P R$ at 15, 30, and 45 min.

The p value of the unpaired students T test at $15 \mathrm{~min}, 30 \mathrm{~min}$, and $45 \mathrm{~min}$ are $0.049,0.045$, 0.031 . Hence the $\mathrm{p}<0.05$ it is statistically significant. 
Table 2 and graph 2: Shows MAP (in $\mathrm{mmHg}$ ) changes in two groups at different time intervals intra operatively.

\begin{tabular}{|l|c|c|c|c|}
\hline & Group P (MEAN \pm SD) & Group D (MEAN \pm SD) & P values & significance \\
\hline Induction & $82.72( \pm 5.58)$ & $84.56( \pm 4.85)$ & 0.229 & NS \\
\hline Intubation & $90.44( \pm 4.56)$ & $92.24( \pm 4.64)$ & 0.161 & NS \\
\hline $15 \mathrm{~min}$ & $87.28( \pm 4.44)$ & $90.2( \pm 4.48)$ & 0.018 & HS \\
\hline $30 \mathrm{~min}$ & $86.88( \pm 4.28)$ & $89.64( \pm 4.13)$ & 0.033 & HS \\
\hline $45 \mathrm{~min}$ & $86.76( \pm 3.45)$ & $89.52( \pm 3.80)$ & 0.008 & HS \\
\hline
\end{tabular}

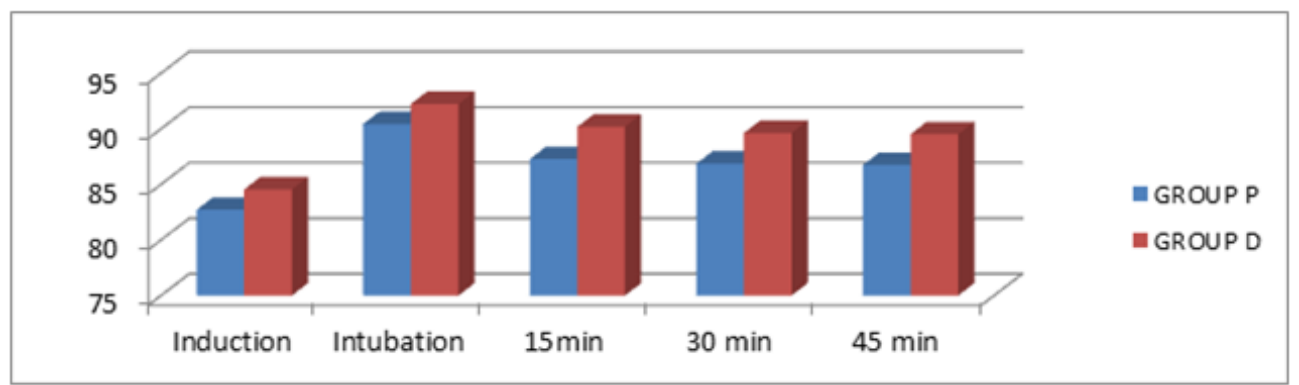

It can be inferred from the values in the table and graph that there is no statistical significant difference between group P and group D during induction and intubation. Slightly lower MAP are found in the Paracetamol group during induction and intubation but there is no statistical significance.

In Group D there is rise in MAP at 15, 30, and 45 min. The p value of the unpaired students T test at $15 \mathrm{~min}, 30 \mathrm{~min}$, and $45 \mathrm{~min}$ are $0.018,0.033,0.008$. Hence the $\mathrm{p}<0.05$ it is statistically significant.

Table 3 and graph 3: Shows the PR (Per minute), MAP (mm of Hg) changes in two groups at the time of recovery.

\begin{tabular}{|l|c|c|c|c|}
\hline PARAMETER & GROUP P (MEAN \pm SD) & Group D (MEAN \pm SD) & P values & \\
\hline PR $(/ \mathrm{mt})$ & $82.16( \pm 4.76)$ & $84.48( \pm 2.95)$ & 0.048 & HS \\
\hline MAP $(\mathrm{mm} / \mathrm{Hg})$ & $86.64( \pm 2.31)$ & $88.4( \pm 3.07)$ & 0.041 & HS \\
\hline
\end{tabular}

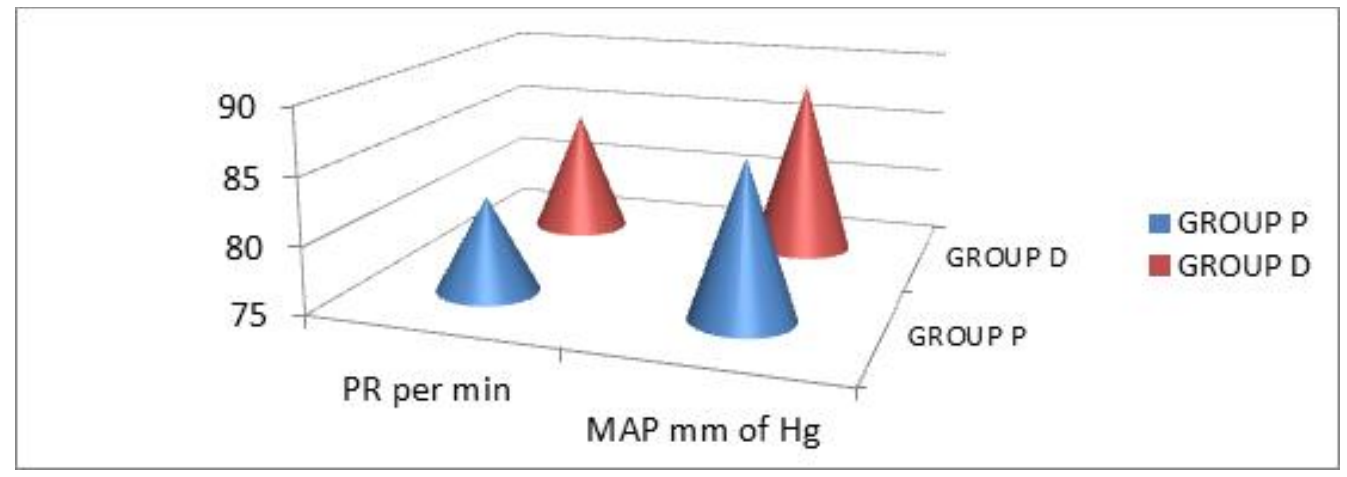


PR and MAP recordings were made at recovery and compared in two groups. There are significantly higher values in the Diclofenac group when compared with Paracetamol group. The $p$ value of the unpaired students $\mathrm{T}$ test for PR and MAP during recovery $0.048,0.041$ hence it is statistically significant.

Table 4 and graph 4: Shows Pulse rate changes in two groups at different time intervals post operatively.

\begin{tabular}{|c|c|c|c|c|}
\hline & Group P (MEAN \pm SD) & Group D (MEAN \pm SD) & P Values & \\
\hline $0 \mathrm{hr}$ & $80.44( \pm 4.50)$ & $83.76( \pm 4.47)$ & 0.013 & $\mathrm{HS}$ \\
\hline $2 \mathrm{hrs}$ & $80.48( \pm 4.83)$ & $83.84( \pm 3.96)$ & 0.015 & $\mathrm{HS}$ \\
\hline $4 \mathrm{hrs}$ & $85.36( \pm 4.66)$ & $82.44( \pm 5.27)$ & 0.027 & $\mathrm{HS}$ \\
\hline $6 \mathrm{hrs}$ & $85.48( \pm 6.02)$ & $82.16( \pm 5.14)$ & 0.045 & $\mathrm{HS}$ \\
\hline
\end{tabular}

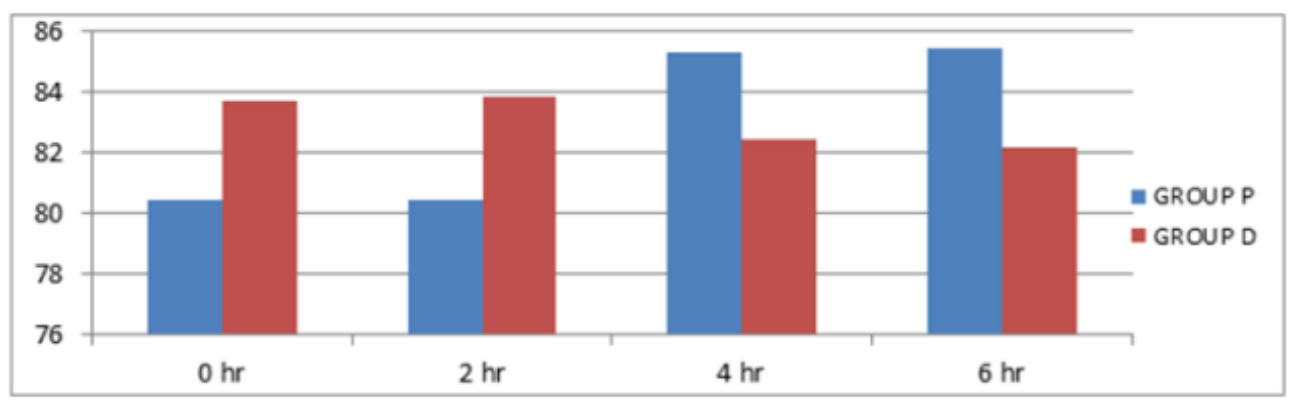

Pulse rate recordings were made at different time intervals during $0 \mathrm{hrs}, 2,4,6 \mathrm{hrs}$ in the postoperative period. Mean pulse rate values significantly higher in Group D at the end of 0hrs and $2 \mathrm{hrs} \&$ in Group P mean PR were significantly high at the end of $4 \mathrm{hrs}$ and 6 hrs. Hence the P Values for unpaired student' $t^{\prime}$ test $(p<0.05)$ they are statistically significant.

Table 5 and graph 5: Shows Mean arterial pressure changes in two groups at different time intervals post operatively.

\begin{tabular}{|c|c|c|c|c|}
\hline & Group P (MEAN \pm SD) & Group D (MEAN \pm SD) & P values & \\
\hline $0 \mathrm{hr}$ & $86.28( \pm 2.53)$ & $87.96( \pm 2.99)$ & 0.041 & NS \\
\hline $2 \mathrm{hrs}$ & $86.16( \pm 2.09)$ & $88.04( \pm 3.25)$ & 0.045 & NS \\
\hline $4 \mathrm{hrs}$ & $89.84( \pm 3.65)$ & $87.36( \pm 3.85)$ & 0.029 & NS \\
\hline $6 \mathrm{hrs}$ & $89.76( \pm 5.46)$ & $86.84( \pm 3.77)$ & 0.031 & NS \\
\hline
\end{tabular}

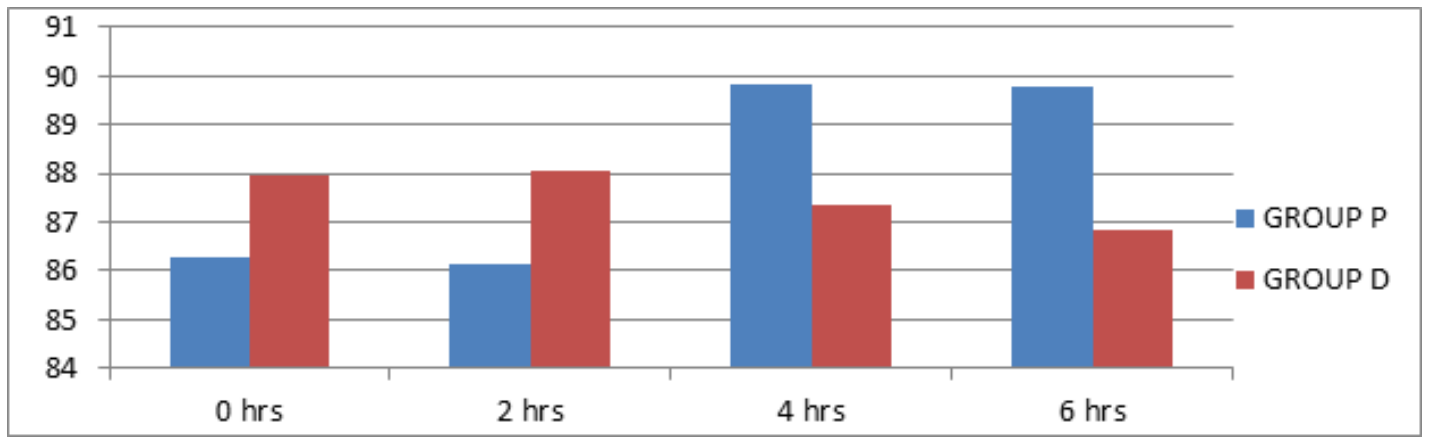


MAP recordings were made at different time intervals during $0,2,4,6 \mathrm{hrs}$ in the postoperative period. It can be inferred from the values in the table and graph that MAP values higher in Group D at the end of 0hrs and 2hrs \& in Group P MAP were high at the end of $4 \mathrm{hrs}$ and $6 \mathrm{hrs}$. Hence the $P$ Values for unpaired student't' test $(\mathrm{p}<0.05)$ they are statistically significant.

Table 6 and Graph 6: Shows pain scores according to VAS at different time intervals in two groups in post-operative period.

\begin{tabular}{|c|c|c|c|c|}
\hline & Group P (MEAN \pm SD) & Group D (MEAN \pm SD) & P values & \\
\hline $0 \mathrm{hr}$ & $2.08( \pm 0.515)$ & $2.40( \pm 0.48)$ & 0.101 & NS \\
\hline $2 \mathrm{hrs}$ & $2.20( \pm 0.44)$ & $2.44( \pm 0.49)$ & 0.247 & NS \\
\hline $4 \mathrm{hrs}$ & $3.689( \pm 1.28)$ & $2.72( \pm 0.53)$ & 0.016 & HS \\
\hline $6 \mathrm{hrs}$ & $3.769( \pm 1.53)$ & $2.44( \pm 0.49)$ & 0.001 & HS \\
\hline
\end{tabular}

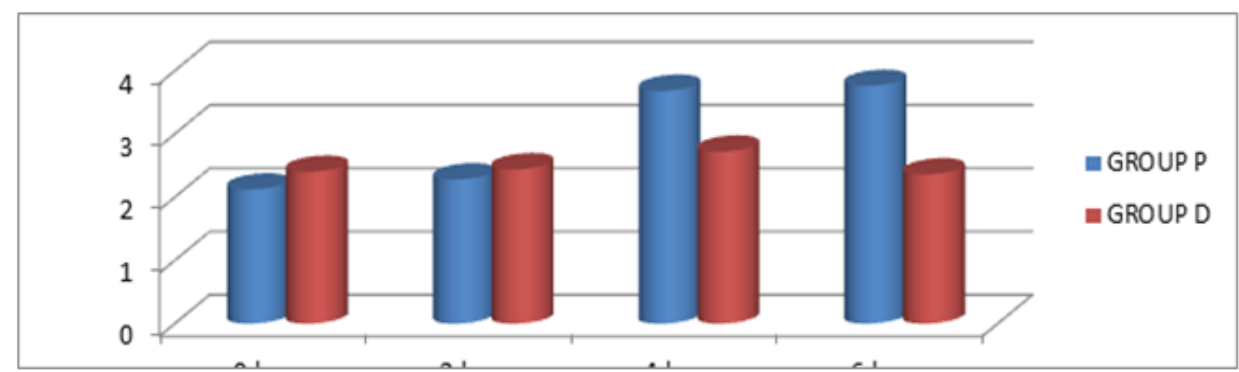

Using VAS the comparison of mean pain scores between two groups post operatively showed: Higher pain scores in Group P at the end of 4 hrs and 6hrs. Hence the P Values for unpaired student's' test $(\mathrm{p}<0.05)$ they are statistically significant.

In Group D pain scores were slightly higher in the first $2 \mathrm{hrs}$ but they are not statistically significant.

Table 7 and Graph 7: Shows temperature recordings at different time intervals in two groups in postoperative period.

\begin{tabular}{|c|c|c|c|c|}
\hline & Group P (MEAN \pm SD) & Group D (MEAN \pm SD) & P values & \\
\hline $0 \mathrm{hr}$ & $98.87( \pm 0.24)$ & $98.99( \pm 0.45)$ & 0.257 & $\mathrm{NS}$ \\
\hline $2 \mathrm{hr}$ & $98.89( \pm 0.28)$ & $99.26( \pm 0.85)$ & 0.049 & $\mathrm{HS}$ \\
\hline $4 \mathrm{hr}$ & $98.94( \pm 0.22)$ & $99.29( \pm 0.84)$ & 0.040 & $\mathrm{HS}$ \\
\hline $6 \mathrm{hr}$ & $98.89( \pm 0.17)$ & $99.32( \pm 0.91)$ & 0.026 & $\mathrm{HS}$ \\
\hline
\end{tabular}

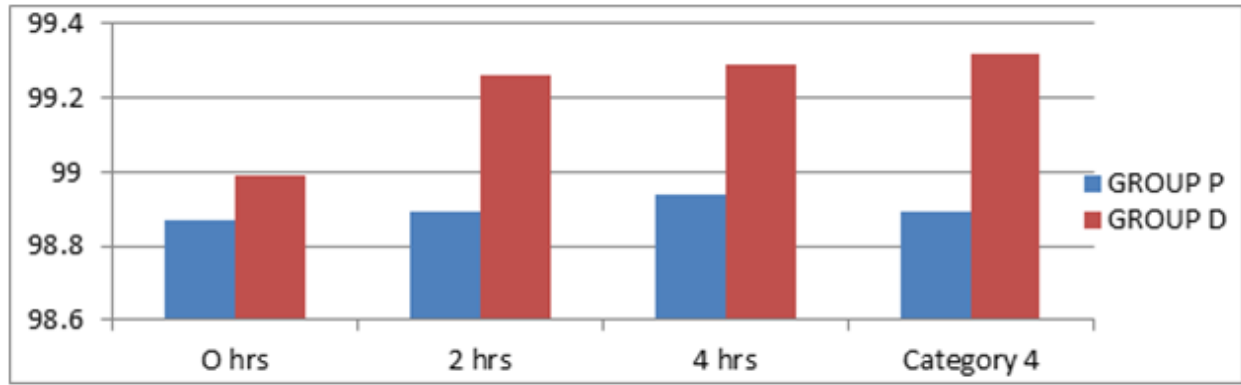


Mean temperatures recorded between two groups post operatively showed: Higher temperature recordings in the Group $\mathrm{D}$ at the end of 2, 4, 6 hrs. Hence the $\mathrm{P}$ value for unpaired student $t$ Test is less than 0.05 they are statistically significant.

DISCUSSION: This study was undertaken to compare the relative efficacy of iv Paracetamol and iv Diclofenac in the relief of intra operative and post-operative pain in elective ENT surgery (i.e., tonsillectomy). All the surgeries lasted around 45min and performed under GA. Patients were selected after a thorough preoperative evaluation.

Patients with H/O hypersensitivity to NSAIDS, Pts having abnormal Liver and Renal function tests, and Pts who are on concomitant medication (anticonvulsants, corticosteroids, or antihistamines) that might interfere with pain evaluation were excluded from the study.

In both the groups there was no stastical difference with respect to their age, weight, Pre-operative pulse rate, Blood pressure and temperature. Patients were divided into two groups with 25 patients in each group. Group I patients received iv paracetamol $15 \mathrm{mg} / \mathrm{kg}$. Group II patients received iv diclofenac $1 \mathrm{mg} / \mathrm{kg} 15$ min before the induction.

All the patients received premedication Fifteen minutes before induction. All the patients received antisialogogue, antiemetic and antacid preoperatively.

Anesthetic technique followed in all the patients irrespective of the group was uniform, general Anesthesia with endotracheal intubation, muscle relaxant and controlled ventilation

In all the patients' average duration of surgery was around $45 \mathrm{~min}$. None of the patients received any other analgesic during intraoperative and postoperative period other than iv paracetamol and iv diclofenac.

All the patients received first dose of the analgesic drug paracetamol/diclofenac 15min before starting the induction.

Patients selected were between 12 and 20 years of age. The mean age in two groups was almost statistically close. Mean age in Group P - $16.68( \pm 2.37)$ \& in Group D 16.76 $( \pm 2.26)$.

The difference in average weight in two groups was also statistically not significant. Mean weight in Group P - 47.76( \pm 8.09$)$ and in Group D - $48.32( \pm 7.91)$.

The difference in average pre-operative pulse rate and blood pressure is also insignificant. Mean Pre-operative Pulse rate in Group P - 79.92( \pm 5.29$)$ and Group D- 79.80( \pm 4.94$)$.Mean Preoperative MAP in Group- P 87.28( \pm 6.36$)$ and Group DX $88.64( \pm 5.64)$. Mean temperature in Group P 98.93( \pm 0.23$)$ and in Group D was - 98.96 $( \pm 0.24)$.

All the patients were followed in the intraoperative period and during recovery for hemodynamic. Recordings were done at induction, intubation and then 15, 30, 45 min. The parameters recorded were pulse rate systolic blood pressure diastolic blood pressure mean arterial pressure. Statistical analysis of the derived parameters were done using unpaired student ' $\mathrm{t}$ ' test and $\mathrm{p}$ value less than 0.05 was considered significant.

PR and MAP recordings were made at 15, 30, 45 min intervals intra operatively and during recovery. There was significant rise in PR and MAP in the Diclofenac group when compared with Paracetamol group.

Subjective assessment of pain relief was studied at $0,2,4,6$, hrs in the postoperative period by both $10 \mathrm{~cm}$ VAS. Vital parameters recorded in addition to pain scores were PR, MAP, and Temperature in the postoperative period at $0,2,4,6 \mathrm{hrs}$. 
Mean pain scores by VAS showed significantly less pain scores in Paracetamol group when compared with Diclofenac at $0 \mathrm{hrs}$ and $2 \mathrm{hrs}$ postoperatively.

At $4 \& 6$ hrs the mean pain scores in Paracetamol group were significantly higher than Diclofenac group. This can be explained due to the difference in pharmacokinetic properties of both the drugs and the short duration of action of Paracetamol and longer duration of action of diclofenac (which produces sustained action over longer periods of time). By 6 hrs most patients in Paracetamol group had significantly higher pain scores requiring top up dose of analgesia (if VAS $>5$ ).

Pulse rate, MAP and Temperature recordings were made at $0,2,4$, and 6 hrs postoperatively. There was significant rise in pulse rate and MAP in Diclofenac group compared to Paracetamol group at $0 \mathrm{hrs}, 2 \mathrm{hrs}$. There was significant increase in PR and MAP at the end of $4 \mathrm{hrs}$ and $6 \mathrm{hrs}$ postoperatively.

NO patient in paracetamol group recorded rise in temperature as compared to diclofenac group in which $24 \%$ of them showed rise in temperature at the end of 2, 4, $6 \mathrm{hrs}$. And the rise in temperature in diclofenac group is not more than $101^{\circ} \mathrm{F}$.

In 1991 Dahl JB, Kehlet $\mathrm{H}^{6}$ : studied the rationale use of NSAIDS in acute painful conditions is on rise, based on improved understanding of pain mechanisms and multimodal analgesia. Prostaglandin mediated inflammatory pain is more specifically and efficaciously treated by NSAIDS than opiods. Availability of parenteral NSAIDS expanded their use especially for management of acute post-operative pain. Parenteral NSAIDS are now widely used pre, intra and postoperatively for pain relief.

In similar study in 2010 Hale Yarkan Uysal, Suna Akin Takmaz, Ferda Yaman ${ }^{8}$ showed the efficacy of iv paracetamol versus iv tramadol for postoperative analgesia after adenotonsillectomy in children. They did a study to evaluate the efficacy and the quality of recovery with IV paracetamol vs iv tramadol for postoperative analgesia after adenotonsillectomy in children. They concluded that The IV formulation of paracetamol was associated with similar analgesic properties and early recovery to that of IV tramadol after adenotonsillectomy in children.

The results of this study show that both Paracetamol and Diclofenac would be effective and well tolerated and the quality of analgesia and temperature control with Parcetamol IV is better than Diclofenac IV during the intra operative, recovery and early postoperative period.

CONCLUSIONS: 50 patients undergoing Elective Tonsillectomy were selected for the study. They were divided into 2 groups of 25 each.

Group P received Paracetamol by IV route and Group D received Diclofenac by IV route. Hemodynamic were assessed during intraoperative period recovery period by monitoring the Pulse rate and MAP and during post-operative period by $10 \mathrm{~cm}$ VAS and monitoring the PR, MAP, and Temp at $0,2,4$, and 6 intervals.

There were no statistically significant differences between the groups with respect to patient characteristics, type of surgery and duration of anesthesia.

The salient observations of the study are as follows: Both Paracetamol and Diclofenac are effective enough for providing predictable intra operative and postoperative analgesia in patients undergoing elective Tonsillectomy. 
Both drugs produce dependable analgesia and are associated with minimal complications, never alarming to warrant an immediate therapeutic rescue.

The quality of analgesia with Parcetamol IV is better than Diclofenac IV during the intra operative, recovery and early postoperative period.

Both groups exhibited hemodynamic stability. Incidence of rise in pulse rate and MAP in the intra operative period and early post-operative period was higher with Diclofenac iv than with Paracetamol iv.

Incidence of rise in temperature during the post-operative period was high with Diclofenac iv than Paracetamol iv.

Paracetamol in our study scores over Diclofenac in providing better quality of analgesia, less incidence of pyrexia and good patient comfort.

Consistent with the pharmacokinetic profile all the patients in Paracetamol group required an additional dose of analgesic (Paracetamol) within $6 \mathrm{hrs}$.

The analgesia with Diclofenac is sustained over longer periods of time.

Studies show that Diclofenac is known to cause gastrointestinal complaints, respiratory and renal effects. We prefer paracetamol as nit does not above side effects.

To conclude that Paracetamol given every $6^{\text {th }}$ hourly parenterally can be used for intra operative and postoperative analgesia (mild to moderate pain) in elective Tonsillectomy)in view of its good quality of analgesia, and its anti-pyretic effect.

\section{REFERENCES:}

1. Melzack R and Wall PD, Pain mechanisms: A new theory, Science, 150: 971-979.

2. Campbell W I, Kendric R Intravenous diclofenac its administration decreases postop pain anesthesia 1990; 45: 763-766.

3. Uysal H Y, Takmaz S A, Yaman F, Baltaci B. The efficacy of intravenous paracetamol versus tramadol for postoperative analgesia after adenotonsillectomy in childrenJournal of Clinical Anesthesia 2011 23, 53-57.

4. Schimdt A, Bjorkman s, Akeson J: Preoperative Rectal diclofenac versus Paracetamol for Tonsillectomy: effects on pain and blood loss. Acta Anaesthesiol sland 2001: 45: 48-52

5. Stage J, Jensen JH, and Bonding P: Post tonsillectomy Haemorrhage and analgesics. A comparative study of acetyl salicylic acid and paracetamol Clin Otolaryngol 1988; 13: 201-4.

6. Dahl JB, Kehlet H: NSAIDS: rationale for use in severe post-operative pain. Br. J. Anaesth 66:7037121991.

7. Uysal H Y, Takmaz S A, Yaman F, Baltaci B, The efficacy of intravenous paracetamol versus tramadol for postoperative analgesia after adenotonsillectomy in children Journal of Clinical Anesthesia 2011 23, 53-57. 


\section{REVIEW ARTICLE}

\section{AUTHORS:}

1. Rupa Kumari A.

2. Deepraj Singh B.

3. Rajshekar Reddy

\section{PARTICULARS OF CONTRIBUTORS:}

1. Associate Professor, Department of Anaesthesiology, Government Medical College, Nizamabad, Telangana.

2. Professor, Department of Anaesthesiology, Osmania Medical College, Hyderabad, Telangana.

3. Resident Specialist, District Hospital, Nalgonda, Telangana.

\section{NAME ADDRESS EMAIL ID OF THE} CORRESPONDING AUTHOR:

Dr. Deepraj Singh,

1-7-145/15,

Opposite Usha Mayuri Talkies,

Musheerabad-500020,

Hyderabad.

Email: drdeepraj@gmail.com

Date of Submission: 05/09/2014.

Date of Peer Review: 06/09/2014.

Date of Acceptance: 17/09/2014.

Date of Publishing: 24/09/2014. 